\title{
Comparative Study on Reproductive Health Awareness between Bio-Science and Non Bio-Science Students of H.S Level of West Bengal Board
}

\author{
Tanima Mukherjee ${ }^{1}$, Abantika Mondal ${ }^{2}$ and Ujjal Kumar Mukherjee ${ }^{3}$ \\ ${ }^{1}$ Assistant Teacher, Jaynagar P.C. Paul Institution, West Bengal, India. \\ ${ }^{2}$ Assistant Professor, Department of Teacher Education, The West Bengal University of Teachers’ Training, \\ Education Planning and Administration, West Bengal, India \\ ${ }^{3}$ Professor, Department of Education, Institute of Education for Women, Hasting's College West Bengal, India \\ E-mail Id: a_aba_aba@yahoo.co.in
}

\begin{abstract}
The study on reproductive health education made an effort to present scientifically the detailed account of the level of knowledge and perception of the school going students regarding reproductive health issues. Main purpose of the study was to make a comparative analysis of bio-science and non bio- science students regarding the awareness and knowledge about reproductive health. 100 school students of different school belong to higher secondary level were selected as sample. Then the survey has been done on them with the help of self made questionnaire. Samples are collected by using stratified random sampling technique. The statistical analysis of the data were done by using independent t-Test. Standard deviation and standard error of the collected data, also calculated to reach a significant conclusion of the study. The statistical analysis of the study found that there is a significant difference in awareness between bio-science and non bioscience students. The bio-science students are more scientifically aware of reproductive health related issues in compare to other than bio-science students. Perception about reproductive health related issues and sex oriented matters are more scientific in bioscience students rather than no bioscience students.
\end{abstract}

Keywords: Reproduction, Reproductive health, biological science students, non biological-science students

\section{INTRODUCTION}

Health is defined by the World Health Organization (WHO) as a 'state of complete physical, mental and social wellbeing'. Sexual and reproductive health (SRH) constitutes a crucial part of general health and a central feature of human development (Geneve, WHO, 2006). According to the World Health Organisation (WHO), reproductive health means a total well-being in all aspects i.e., physical, emotional, behavioral and social.

Adolescents are the age of storm and stress. This is the period of exploration and experimentation. According to the World Health Organization (WHO) Expert Committee, adolescence is defined as the period between 10 and 19 years, the second decade of life.

During this period many adolescents engage in their first sexual practices that are prone to reproductive health problems lasting into adulthood (El-Kak, 2013, Raheel et al, 2012, WHO, 2014). Adolescents are also more vulnerable because of their lack of knowledge about STIs and their involvement in risky sexual practices, including early sexual initiation, unsafe sex, multiple sexual partners, and inconsistent condom use (Epstein et al .,2014 and lee et al.,2014). Sex education or Reproductive health education has a broad aspect that aims to build a strong foundation for lifelong sexual health by acquiring scientific information and attitudes, beliefs and values about one's identity, relationships, character and intimacy.

Science students get to know about reproductive system, its functioning, its related health and hygine easily from biological science subject. Biology education is needed not only for creating biologically literate citizens but also reproductive health sensitive human beings. This study focused on the analysis of the impact of biology on students awareness about reproductive health and sex oriented issues.

Study also try to find out their attitude toward reproductive health and healthy sex oriented issues. Study also measures how much they are liberal or open minded to discuss about such things? and how much our community are ready to introduce such education in schools?

Up to class in our education system all students come to contact with biological science. But up to class 10 biological sciences mainly encompassed with amphibians reproductive system. But human beings are mammals higher class than amphibians. So students who read biological science only up to class 10 it will be difficult to come in contact with the scientific and proper knowledge about human reproductive system and human reproductive health. So it is very essential to develop a proper awareness and attitude towards sex and reproductive health oriented issues.

In this context Non science students and Science students but non biological science students fall in the same level and category. It does not mean all science students (mainly without biological science) have proper knowledge about the issue. This Study reveals the difference between biological and non biological science students about the 
proper knowledge, awareness and attitude towards sex and reproductive health oriented issues.

\section{METHODOLOGY}

Population: In the present study the population was all the secondary school students of Kolkata. Sampling: 100 students were randomly selected for the study. Samples were a true representative of population among the all students of Kolkata at higher secondary level.

Data collection tool: data were collected by survey technique. Self made questionnaires were used for the survey. Questionnaires standardized according to the protocol.

Statistical analysis: Statistical analysis was done by t-test. Standard deviation and standard error of the collected data, also calculated to reach a significant conclusion of the study.

\section{RESULTS}

The Figure 1 shows bio science students scored in percentage which is higher than the the non bio-science students scores in percentage. The Table 1 shows that the calculated $\mathrm{t}$ value is much higher than the critical value at $5 \%$ level of significance when the degree of freedom is 98 . Therefore the null hypothesis is completely rejected that is there is a significant difference in awareness of reproductive health between bio-science and other that bio-science students.

Figure 1 also shows the comparative score (in percentage ) between bio-science students and non bio- science students in respect of awareness of reproductive health.

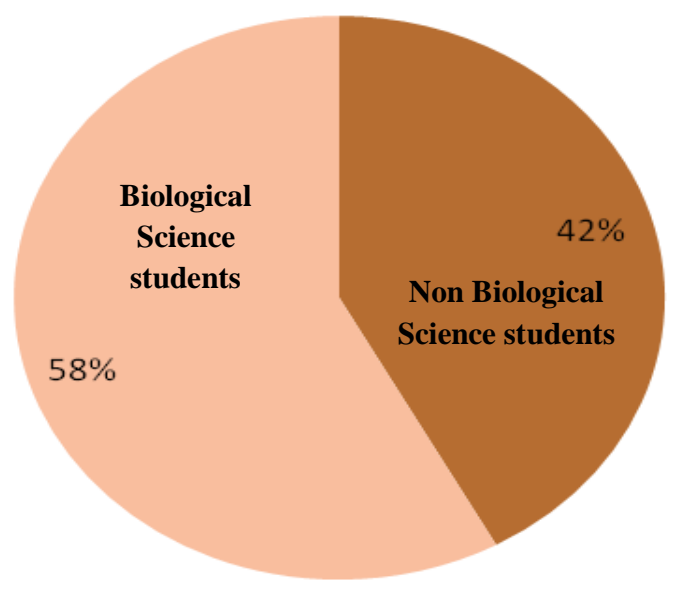

Fig. 1 comparative score (in percentage ) between bio-science students and non bio- science students in respect of awareness of reproductive health.
TABLE I THE TABLE SHOWS THE T VALUE OF TWO VARIABLE (BIO-SCIENCE STUDENTS AND NON-NON-SCIENCE STUDENTS)

\begin{tabular}{|c|c|c|}
\hline \multicolumn{3}{|c|}{ t-Test: Two-Sample Assuming Equal Variance } \\
\hline & Bio & Non bio \\
\hline & science & science \\
\hline & students & students \\
\hline & score & score \\
\hline Mean & 11.72 & 3.28 \\
\hline Variance & 4.409796 & 12.49143 \\
\hline Observations & 50 & 50 \\
\hline Pooled Variance & 8.450612 & \\
\hline Hypothesized Mean & 0 & \\
\hline Difference & & \\
\hline Df & 98 & \\
\hline t Stat & 14.51672 & \\
\hline $\mathrm{P}(\mathrm{T}<=\mathrm{t})$ one-tail & $1.84 \mathrm{E}-26$ & \\
\hline t Critical one-tail & 1.660551 & \\
\hline $\mathrm{P}(\mathrm{T}<=\mathrm{t})$ two-tail & $3.69 \mathrm{E}-26$ & \\
\hline t Critical two-tail & 1.984467 & \\
\hline
\end{tabular}

\section{DISCUSSION}

According to census 2011 about 434430 male and 549400 female populations respectively are there in India who are aged in 15 to 19 years out of where $19.47 \%$ of the female were married under the age of 15 years. The average number of children had born per woman under this age had reached. Also the mother mortality rate which is about 1.3/1000 people (Youth India Survey,2017,https://censusindia.gov.in/census_and_you/age _structure_and_marital_status.aspx). Adolescent mothers are at high risk of maternal mortality . It is the opportune time during adolescence (10-19 years) when young people experience developmental changes in their physiology and behaviour as they enter adulthood (Geneva, WHO, 2011)Government of India has recognized the importance of influence of health seeking behaviour of adolescent. Implementation of sex education in school curriculum was the reflextion of government recognition of the reproductive 
health education. Highlight of India Today, a well known news channel reveals that initiatives have been taken by the government to impart 22 hours school health programs to benefit 26 crore adolescent, joint initiative of union health ministry and MHRD (NACO,2016-2017) and National Strategic Plan for HIV/AIDS and STI, 2017.

However, the existence of strong stigma and controversy related to adolescent health programs or reproductive health education or education related to sex or life style education, handicaps to solve the problems related to adolescent health. It also being incomprehensive and failing to fully address the main health issues related to adolescents health and becomes the issues more vulnerable day by day. These indulge several negative sexual and reproductive health outcomes, like early and closely spaced pregnancy, unsafe abortions, sexually transmitted infection (STI), HIV/AIDS, and sexual violence, the rates of which are already increasing at a disturbing rate (Geneva, WHO, 2010).

It is also a threat to expose a sexually implicit content on the television and internet is more likely to initiate early/premarital sex, unsafe sex or relationship, which comes with a host of negative implications which they often find themselves unequipped to deal with. This applies to a quarter of India's young people who indulge in premarital sex (Shashi Kumar et al.,2013, Shajahan et al.,2015). It also indulges absurd imagination related to sex or sexual life. It also promotes the crimes or violence related to sex towards opposite gender.

More importantly, adolescents (15-24 years) contribute to a disproportional $31 \%$ of AIDS burden in India, despite the whole demographic comprising about $25 \%$ of the country's population. UNAIDS reported there were 2300,000 people of 15 years and above, living with HIV in India, with one youth infected with HIV/AIDS almost every $15 \mathrm{~s}$ (Population Foundation of India, 2003). (UNICEF; 2010.) $18 \%$ (1.2 billion) of world's population in 2009 , with $88 \%$ living in developing countries. India has the largest adolescent population (243 million with more than 50\% of the adolescent population living in urban areas).

These figures indicate the importance of specifically addressing the healthcare needs of this considerable demographic, particularly for the developing countries such as India.(Tripathi and Sekher, 2013).

In India, the question arises whether we have even reached the point where we speak the word freely without apprehension regarding reproductive issues, sex education and life style education. Unfortunately, sex education or human reproductive health related topics or life style education in most of the schools even today is limited to the education of sex in amphibians and animals like Frog and Rat etc and when it comes to the point of Teaching and Learning about sex organs and sex related issues in class room, teachers generally just breezes through with just the basic introduction to the reproductive parts. In fact some schools in the name of imparting sex education conduct workshops on health and Hygiene. This study represented that students came in more contact with biological science get more opportunity to learn about reproductive health and also body parts related to reproductive health. They are biologically aware about the reproductive health, risk, procedure, common health and hygiene various disease related to reproductive health, there precaution intervention, severity birth rate and control devices, their importance and the importance of sex education in school. So the study find out the present situation and may provide valuable suggestion to policy makers and decision maker to take reasonable steps to impart awareness programme among school students mainly from the very beginning adolescent stage Every students should have minimum or basic knowledge about reproductive health and also body parts related to reproductive health. School is the miniature of society and parents are the important stakeholder of education system. So their involvement is also desirable.

\section{CONCLUSION}

The study of the reproductive health awareness among the students at higher secondary level at Kolkata reveals that there is a difference between the students of bio-science and non bio-science students. Bio- science students are more open to discuss about common health and hygiene, well known about sexually transmitted disease ,various birth control technique, effect of increasing growth of population. Reproductive health is an important element for overall health of a human being. Lack of proper awareness about reproduction and reproductive health related issues become a major factor behind some crime. Healthy youth is the pillar of nation. Proper awareness regarding these issues plays a major role to create a healthy youth as well as healthy society.

Sometimes implementation of Sex Education or Life style education "Jibon Saili" in school curriculum faced a very difficult situation for the protest of maximum number of teachers, parents and from different corner of our society. So various strategies should be taken in school curriculum for all students irrespective of subjects for make them aware about overall concept of reproductive health and reproductive health elated issues to our society healthier. Bioscience students are more scientifically aware about sex oriented and reproductive health related issues. So a basic level awareness is very necessary for a healthy society so up to the end of school education it is necessary to run the classes about sex and reproductive health oriented issues. This help the non bioscience students also to know such kind of issues from a scientific background

\section{REFERENCES}

[1] Geneva: WHO. (2006). WHO. Defining sexual health.

[2] El-Kak, F. (2013). Sexuality and sexual health: constructs and expressions in the extended Middle East and North Africa. Vaccine, 31, G45-50. 
[3] Raheel, H., Mahmood M. A., \& BinSaeed A.(2012). Sexual practices of young educated men: implications for further research and health education in Kingdom of Saudi Arabia

(KSA).

J Public Health, 35, 21-26.

[4] World Health Organization (WHO). (2014). Health for the World's Adolescents: A second chance in the second decade.

[5] Epstein, M., Bailey, J.A., Manhart, L.E., Hill, K.G., \& Hawkins J. D. (2014). Sexual risk behavior in young adulthood: broadening the scope beyond early sexual initiation. J Sex Res. 51, 721-30.

[6] Lee, Y.M., Cintron, A., \& Kocher, S. (2014). Factors related to risky sexual behaviors and effective STI/HIV and pregnancy intervention programs for African American adolescents. Public Health Nurs. 31, 414-27.

[7] Geneva: WHO. (2011). The sexual and reproductive health of younger adolescents research issues in developing countries: Background paper for a consultation.

[8] Retrieved from Annual Report 2016-2017, NACO.

[9] Retrived from National Strategic Plan for HIV/AIDS and STI, 2017 -2024, December,2017.

[10] Geneva: WHO. (2010). World Health Organization. Measuring sexual health: Conceptual and practical considerations.

[11] Shashi Kumar, R., Das, R.C., Prabhu, H.R., Bhat, P.S., Prakash, J., \& Seema, P. (2013). Interaction of media, sexual activity and academic achievement in adolescents. Med J Armed Forces India. 69, 138-43.

[12] New Delhi: UNICEF. (2010). Adolescents in India. Desk Review Report of Existing Evidence and Behaviours, Programmes and Policies Report.

[13] Tripathi, N., \& Sekher, T.V. (2013) Youth in India ready for sex education?. Emerging evidence from national surveys. PLoS One. 8, e71584.

[14] Shajahan, I., Shajahan, A., Sathyanarayana Rao, T.S. \& Wylie, K. (2015). Adolescent sex education in India: Current perspectives, Public Health Nurs 32(4), 333-337.

[15] Retrieved from https://censusindia.gov.in/census_and_you/ age_structure_and_marital_status.aspx. 